\title{
Research on the Innovation Direction of Inland Free Trade Area Construction Policy
}

\author{
Cheng Yan
}

School of Economics and Finance, Wuhan Business University, Wuhan, Hubei, 430056, China

Keywords: Innovation Direction, Inland Free Trade Area, Construction Policy

\begin{abstract}
As China's economy enters the "new normal", China's regional coordinated development has also entered an important period. The construction of free trade zones in inland areas is of great significance for accelerating the development of inland areas. The development conditions of China's inland regions are different from those in Shanghai and Guangzhou. It is urgent to explore the development path of free trade zones under the background of industrial transfer in inland areas. The construction of free trade zone in inland areas of China should combine the characteristics of location, identify its functional orientation, build an efficient management mode, build on the basis of studying coastal areas, adapt to local conditions, do a good job in industrial undertaking and corresponding trade logistics platform construction and financial service innovation.
\end{abstract}

\section{Introduction}

Accelerating the implementation of the free trade pilot zone strategy is an important part of China's new round of opening up. On April 1, 2017, seven free trade pilot zones in Sichuan, Liaoning, Zhejiang, Henan, Hubei, Chongqing and Shaanxi were officially listed, marking a new voyage from the pilot exploration stage to the mature development of the free trade zone. Except for the coastal areas of Zhejiang and Liaoning, the remaining five regions of the third batch of free trade zones are located inland in the central and western regions and belong to the inland free trade pilot zone (hereinafter referred to as the "inland free trade zone"). On the strategic path, the Inland Free Trade Area is accelerating the replication and promotion of the mature experiences, models and practices of the four established free trade zones to achieve its "national function" everywhere; on the other hand, it is combined with these provinces. The advantage of land location highlights the "regional characteristics" and realizes the linkage and spillover effects on the surrounding areas, that is, mainly focusing on the central and western regions, taking into account the northeast region and the eastern region, respectively docking the "Belt and Road", the Yangtze River Economic Belt, the rise of the central region, and the development of the western region. And other major national development strategies. As an important platform and pivot for inland opening, the path of "accelerating development" in the free trade zone is "reliance on deepening reform and opening up". The main body is the new economic momentum driven by the digital economy and the platform economy, as well as the integration, synergy and sharing. Create an ecological environment.

\section{The development of inland free trade zone will help foster new kinetic energy development}

The emergence of new technologies has broken the old spatial order structure, increased productivity, and led to new changes in production relations and production efficiency. The Internet of Things and Intelligent Drive New Inland Free Trade Zone to nurture new kinetic energy focuses on institutional innovation Yu Rongling's business model, thus creating more sharing value. Take the advanced manufacturing and high-end productive service industries that are developed in the inland free trade zone as an example. Many small and medium-sized enterprises have become the traditional industries that promote manufacturing and circulation through mass entrepreneurship and innovation to help intelligent, green and service upgrades. The power that cannot be ignored in transformation. As a platform engine for inland open innovation, the platform economy built by the Free Trade Zone pays more attention to the potential small and medium-sized market, the changes 
in the demand of the retail market, and the key role of the market terminal "last mile" in improving service quality. Supported by this time and place, the third batch of free trade zones, especially those in Sichuan and Chongqing except Zhejiang and Liaoning, registered more than 40,000 new market entities as of the end of 2017, and more than $90 \%$ of them are average registered capital. SMEs of about 20 million yuan.

Since the listing, the new economic sectors of the inland Free Trade Zone have been active in innovation and entrepreneurship in the form of digital economy and platform economy. They have solved excess capacity and driven a large number of jobs, showing great development vitality and potential, relying on differentiated development and interconnection. New advantages such as open system, forming a regional development strategy pattern for countries along the "Belt and Road", promoting various new economic kinetic energy to accurately match market demand and social massive innovation resources, actively exploring new modes of open economy operation management, and building openness Key tasks such as the new industry system have become the "new force" of inland economic and social development. From the perspective of big data content analysis and value chain evaluation, more than $80 \%$ of enterprises in the inland free trade zone have highlighted the distinctive features of "four new" and "four modernizations", namely, through new technologies, new industries, new formats, and new models. Realize industrial intelligence, smart industrialization, cross-border integration, and high-end brand. From the perspective of the newly registered SME innovation and entrepreneurship segment in the Free Trade Zone, the main trend is to seize a "key" and implement four "leading" to create an ecological, that is, to seize the key to the next generation of information technology and implement Innovative production methods led by intelligent manufacturing, consumption upgrading and innovation led by the Internet of Things, trade upgrading and innovation led by the "Internet + " cross-border platform, and production service innovation led by the upgrading of financial factors, creating a large-scale investment and entrepreneurship SMEs integrate innovative ecology. All inland free trade zones focus on the key aspects of the supply side, make full use of the full empowerment advantages of institutional innovation, and explore the introduction of policy documents that support enterprises to enhance competitiveness, promote technological innovation, and prioritize talent development, through precise and combined Policy supply, release new kinetic energy to develop vitality, promote the rapid development of the new economy, and create a new economic industrial system with outstanding characteristics and strong competitiveness.

\section{Inland Free Trade Zone is challenging to cultivate new kinetic energy}

In the process of developing a new economy and nurturing new kinetic energy, the new kinetic energy and new model of inland development face common difficulties and challenges. At the same time, there are problems such as fragmentation of reform and innovation, insufficient coordination among various departments, and inland trade. The development of new kinetic energy in the district constitutes a deep challenge. (1) The short duration of market entities is due to the intrinsic "hard injury" of logistics and capital costs, the mutual penetration, integration or fission of small and medium-sized enterprises with platform-type and digital innovation modes, and the lack of innovative and entrepreneurial service platforms. The long-term role, the growth and development of SMEs is unstable. From the survey of enterprises in the Free Trade Zone, nearly 40\% of enterprises will be replaced by SMEs every year, but many of them are not reflected in the industrial and commercial registration. According to the sampling situation, the average life expectancy of SMEs in the inland Free Trade Zone is short, and the average duration of life is less than 3 years, which is far from the 8.2 years in the United States and 12.5 years in Japan.

At present, the foreign investment policies of their respective trade zones, despite certain innovations, are generally within the framework of the original coastal policy, lacking substantive policy innovations suitable for inland openness; industrial parks are small and scattered, and the positioning is blind and empty, and the supporting conditions are relatively low. Excellent; lack of high-level cross-administrative regional coordination mechanism, each fighting, the obvious trend is obvious. From the comparative analysis of their respective trade districts as of December 2017, the 
number of registered foreign-funded enterprises accounted for the vast majority of the types of foreign-funded enterprises in the market, and the proportion of registered foreign-invested enterprises was small. From the comparison of the coastal and inland free trade zones, although the total number of enterprises in the Zhejiang Pilot Free Trade Zone is small, the average registered capital is significantly higher than the inland free trade zones.

\section{Policy recommendations for cultivating new kinetic energy for economic development in the Inland Free Trade Area}

In order to build a new open economic system and accelerate the pace of opening up to the outside world, we should continuously improve the key points of the global supply chain for customs clearance efficiency, and incorporate the procedures related to the trade of goods and services in the new kinetic energy industry into the "single window". In the fields of certificate declaration, tax payment, customs clearance and free trade zone innovation system, we will continue to make "addition" in innovation, and create a smart supply chain platform that adapts to the new consumer market. At the same time, it is a good production enterprise with good credit. The main commodities will be audited and filed, and the machine inspection will be carried out in the export sector. The customs clearance time will be shortened, the standard and the international level will be improved, and the comprehensive logistics efficiency of the inland free trade zone will be continuously improved. Going to the "multiplication" effect of trade facilitation.

In order to break the restrictions on different administrative divisions in the free trade zone, within the zone and beyond, and between districts and districts, the basic premise of the development of new kinetic energy that complements the production factors and the efficient flow of information data should be innovative. The economic cooperation mechanism cooperates in the construction and development of various economic and industrial parks in specific regions, and achieves a mutually beneficial and win-win regional economic development model through cooperation and coordination mechanisms such as planning, construction, management and benefit distribution. By exerting comparative advantages in different regions, strengthening resource intensive conservation and utilization, improving development results sharing mechanisms, accelerating unified market construction, promoting free and orderly flow of factors, and making new contributions to promoting regional coordinated development.

Many SMEs in the Inland Free Trade Zone have become smart forces that can promote the transformation and upgrading of the manufacturing industry through mass entrepreneurship and innovation. By creating the "Made in China 2025" demonstration matrix, large and medium-sized enterprises should be integrated into the cluster in the region, the service industry and the manufacturing industry will be organically combined, and new modes such as networked collaborative $R \& D$ and manufacturing will be developed to form an intelligent manufacturing inland innovation atmosphere. Industrial clusters. At the same time, all pilot areas should be encouraged to fully explore the innovation and empowerment of administrative supervision legislation, and accelerate the establishment of new kinetic energy industry basic supervision standards in line with international standards: in the field of life service industry, focus on accelerating the construction of regulatory standards such as big health and Internet education; In the field of sexual services, the focus is on accelerating the construction of regulatory standards such as Internet finance and cross-border financial leasing. As soon as possible, it will be in line with international standards, establish a unified anti-monopoly system, substantially enhance the effectiveness of anti-monopoly, and create a fair and competitive market environment for all types of emerging market entities.

The accelerated development of the Internet, Internet of Things, big data, cloud services, cloud computing and smart technologies has triggered profound changes in consumption patterns and traditional formats. The international trade approach has presented a new cross-border, multilateral, diversified and diverse And a networked link. Each inland free trade zone should accelerate the formation of a B2B2C regulatory system and accelerate data sharing and in-depth use of transaction information, financial information, logistics information, and regulatory information. The gap 
between high-standard rules should be filled around cross-border e-commerce, and the experience of the inland free trade zone should be upgraded to the Chinese model and the Chinese digital trade plan should be formed. The new economy and the old system are in a dilemma. Only from "management" to "governance" and effectively building an internationally advanced market supervision system is an effective "antidote." The SME Development Promotion Organization shall be established in the market supervision departments of the Inland Free Trade Zone. The main function is to formulate and implement the supervision rules for improving the business environment in accordance with the SME Promotion Law. If the principle of "inclusiveness and prudence" should be adhered to, it is not easy. Label the new format and new model with a monopoly, and accelerate the exploration of a new regulatory framework for "government supervision platform and platform supervision individual". At the same time, focusing on the development characteristics of emerging industries, creating a system of discretionary disciplinary punishment with greater capacity and unimpeded information sharing between the free trade zones, so that the inclusive financial services and rights protection based on the "data value" of the whole life cycle of SMEs can be implemented. .

\section{Conclusion}

Exploring the model of "micro-reconstruction and great promotion" in the free trade zone, continuously improving the sense of community and human touch, imprinting urban cultural memory and optimizing the quality of public space. At the same time, we can make full use of the existing "double-creative" project bases in various regions, and build a community of exchange activities with industry-sharing and complementary advantages around areas such as reform and innovation in the free trade zone and policy integration.

\section{References}

[1] Zhang Yiyan. Discussion on the development path of Jiujiang's foreign trade under the background of Changjiu economic integration [J]. Knowledge Window, 2018, 0 (8): 86-87.

[2] Chen Shibang. Research on the combination of talents training in higher vocational international trade practice engineering [J]. Modern Economic Information, 2018, 0 (5): 398-399.

[3] Rong Aiping. The history and future of Shanxi's economic development—after reading "Economic Geography of Shanxi" [J]. Economic Issues, 2018, 0 (5).

[4] Xi Huimin. Strategic Transformation of "Coal Capital" to "Tianxia Datong" from the Perspective of Competitiveness [J]. Economic Outlook of the Bohai Sea, 2018, 0(3): 80-80.

[5] Zhang Yansheng: Three Judgments on the Prospects of Sino-US Trade Warfare [J]. Economic Research Information, 2018, 0(4): 54-55. 